\title{
Utility of Preoperative CA125 Assay in the Management Planning of Women Diagnosed with Uterine Cancer
}

\author{
N. Povolotskaya, N. Das, K. Dhar, D. Brinkmann, F. Gardner, and R. Woolas \\ Portsmouth Cancer Centre, Queen Alexandra Hospital, Southwick Hill Road, Cosham, Portsmouth, Hampshire PO6 3LY, UK \\ Correspondence should be addressed to N. Povolotskaya; natalia.povolotskaya@gmail.com
}

Received 30 October 2013; Accepted 15 January 2014; Published 27 February 2014

Academic Editor: Giampiero Capobianco

Copyright ( 2014 N. Povolotskaya et al. This is an open access article distributed under the Creative Commons Attribution License, which permits unrestricted use, distribution, and reproduction in any medium, provided the original work is properly cited.

\begin{abstract}
Objective. This study assesses the role of preoperative serum CA125 levels in the planning treatment options for women diagnosed with uterine cancer. Material and Method. Ninety five consecutive patients diagnosed with uterine cancer during a four-year period were identified. Age ranged from 35 to 89 years with a mean age of 69 years. The preoperative CA125 levels were dichotomised at $28 \mathrm{U} / \mathrm{mL}$ (using ROC analysis to identify the best discriminating threshold for 5-year survival). This level was then correlated with preoperative prognostic indicators: patient age, tumour grade, and histopathological tumour cell type. Survival data was plotted using Kaplan-Meier curves and analysed using the log-rank test. Univariate and multivariate analysis were performed to identify the predictors of overall survival. Results. The mean age of patients was 69 years (range: 35-89). On univariate analysis, the use of preoperative CA125 levels of greater or less than $28 \mathrm{U} / \mathrm{mL}$ correlated significantly with age $(P=0.01)$, the grade of disease $(P=0.02)$ and unfavourable tissue type $(P=0.03)$. This threshold CA125 level had a sensitivity of $75 \%$, specificity of $76 \%$, positive predictive value of $35 \%$ and negative predicative value of $96.25 \%$, and a likelihood ratio of 3.12 for predicting nodal disease. Using a threshold of preoperative CA125 level of $28 \mathrm{U} / \mathrm{mL}$ (area under curve: 0.60 ) was also a significant predictor of 5-year survival (log-rank test, $P=0.01$ ). Using Cox multivariate survival analysis to identify predictive preoperative factors overall, unfavourable cell type was the strongest predictor of survival (Chi square $=36.5, \mathrm{df}=4$, and $P=0.001$ ), followed by preoperative CA125 level (CA125 $>28 \mathrm{U} / \mathrm{mL}, P=0.011)$ and unfavourable preoperative grade $(P=0.017)$. Amongst patients with a favourable histological tissue type (endometrioid), preoperative CA125 levels predicted overall survival (Chi square $=6.039$, $\mathrm{df}=2, P=0.02$ ); however unfavourable preoperative grade did not $(P=0.5)$. Overall, at five-year follow-up, while there were no deaths among the women with preoperative serum CA125 less than $12 \mathrm{U} / \mathrm{mL}$, eleven of the twenty-three deaths (47.82\%) in the study occurred in women with a preoperative CA125 more than $28 \mathrm{U} / \mathrm{mL}$. Conclusions. A preoperative CA125 assay for women with uterine cancer is a relatively inexpensive, reproducible, and objective test which provides valuable information regarding the risk of metastatic disease and overall likelihood of long term survival. Patients with a low likelihood of metastatic/nodal disease (favourable tissue type and CA125 level $<28 \mathrm{U} / \mathrm{mL}$ ) and significant comorbidities may benefit from avoiding an extended complete staging procedure. Alternatively, a high level of CA125 may prompt further imaging and multidisciplinary discussions to plan for individualised management and consideration for recruitment to clinical trials.
\end{abstract}

\section{Introduction}

Endometrial cancer is the fourth most common cancer in women in the UK with 7,703 cases diagnosed in 2008 accounting for $5 \%$ of all female cancers [1-3]. Estimated life time risk of developing uterine cancer for women in the UK is 1 in 46 [4]. The number of cases diagnosed annually is expected to rise $[5,6]$. The rise in deaths follows the increase in the number of women being diagnosed with uterine cancer, with its incidence rising by 43 percent since the mid-1990s, from 13.7 to 19.6 per 100,000 [3]. Although survival from uterine cancer continues to improve gradually, more women are in fact dying from the disease, because of the rise in numbers of women being diagnosed [7].

Many women presenting with endometrial cancer are elderly [3, 8] and often have significant co-morbidities. Patients who present with disease confined to the uterus have a good prognosis while those with advanced stage disease have a higher risk of recurrence and death. Since 1988 the International Federation of Gynaecology and Obstetrics 
(FIGO) has recommended a complete surgical staging (last revised in 2009 [9]) as the initial treatment for women diagnosed with corpus cancer [10]. A complete surgical staging is not an option for a group of women with significant co-morbidities that increase their risk for adverse intraoperative and post-operative outcomes. Individualisation of the extent of surgical staging procedure for women with uterine cancer requires a careful appraisal of preoperative prognostic information and a flexible approach on the part of the appropriately trained surgeon [11].

At present patient age, histological cancer type [12-14], preoperative grade $[15,16]$, imaging evidence of degree of myometrial invasion [17-20], and the presence of metastatic disease are used to predict the group of patients with high risk of recurrence preoperatively and optimise individualised treatment accordingly [11, 21, 22]. Unfortunately none of these features are able to predict the metastatic potential of the disease with certainty. Preoperative grade of disease following an outpatient biopsy by pipelle sample or endometrial curettage is inaccurate, with up to forty percent of the patients being upgraded after surgery [23-29]. Preoperative imaging techniques, used to identify myometrial invasion and metastatic disease, have similar problems; they are often expensive, have varied accuracy, and may not be available universally $[18,30]$. New molecular markers techniques (e.g., loss of ER/PR expression [31], P16 expression, high expression of P53 [32, 33], high proliferative rate (Ki-67) [34], high expression of stathmin [35], overexpression of Her2NEU [36], and aneuploidy [37]) have been studied in hysterectomy and preoperative uterine biopsy with a high degree of correlation between the results. However practical clinical use of these markers awaits further evaluation.

Since the discovery of CA125 in 1981 by Bast et al. [38, 39] there have been a number of reports about this glycoprotein and its role in endometrial cancer [40]. Niloff initially reported elevated levels of CA125 in patients with advanced stage and recurrent endometrial cancer [41]. Several reports then followed reporting elevated levels in both primary and recurrent endometrial cancer [42-56]. In a retrospective review of 210 women with endometrial cancer, Sood et al. found elevated serum CA125 levels to be a strong predictor of extrauterine disease and mortality. A management algorithm based on preoperative CA125 levels and the validity of the use of the vaginal hysterectomy in a specific group of patients with endometrial cancer was also presented [57-59]. Clinically it will be extremely useful to have an inexpensive and objective test for preoperative identification of the patients, who have a high likelihood of extrauterine disease and poor prognosis for overall survival. Such a test could be utilised to determine what preoperative investigations are appropriate and what treatment options may be suitable.

This study evaluated preoperative CA125 levels as a marker of metastatic potential and predictor of overall long term survival in patient with uterine cancer. This study also explores the role of CA125 in identifying women who may benefit from various treatment options available for women with this disease.

\section{Materials and Method}

During a four-year period (1997-2000) patients with the diagnosis of uterine cancer were identified from a prospectively collected data base at the St. Mary's Hospital, Portsmouth. All our patients were staged according to the FIGO guidelines. Following the diagnosis, patients underwent surgical staging which included a total abdominal hysterectomy, bilateral salpingo-oophorectomy, omental biopsy, and peritoneal washings with or without lymphadenectomy depending on preoperative risk factors. Adjuvant treatment where indicated was recommended following multidisciplinary discussions and as per departmental protocols. All patients had their serum CA125 levels measured as part of preoperative assessment. Demographic, operative, histopathological data were documented prospectively and five-year survival data (disease related morbidity) was collected from the oncology data base or review of the case notes as required. Receiver Operative Curve (ROC) analysis was used to identify the best discriminating threshold of the preoperative serum CA125 levels for overall survival. This level was then correlated with the tumour grade, cell type, lymph node involvement, and the stage of the disease. For the purpose of analysis histopathological tissue type was categorized into favourable (endometrioid) and unfavourable (squamous, clear cell, carcinosarcoma, and serous) groups. Survival data was plotted using Kaplan-Meier curves and analysed using a log-rank test. Univariate and multivariate analysis (Cox proportional hazard) were performed to identify predictors of overall survival as well. All analyses were performed using SPSS version 11 statistical package.

\section{Results}

Ninety-five patients diagnosed with uterine cancer were identified during a four-year period of time (1997-2000). Ages ranged from 35 to 89 years with a mean 69 years. All patients underwent surgical staging which included a total abdominal hysterectomy, bilateral salpingo-oophorectomy, omental biopsy, and peritoneal washings; $32 \%$ of the patients with either unfavourable tissue type or high tumour grade on preoperative histology underwent a pelvic +/- para-aortic lymphadenectomy as well. Table 1 shows the distribution of patients with respect to age, preoperative grade, and stage of the disease. CA125 levels ranged from 4 to $975 \mathrm{U} / \mathrm{mL}$ (with a median of $19 \mathrm{U} / \mathrm{mL}$ ). Patients were divided into two groups based on preoperative CA125 levels $(</>28 \mathrm{U} / \mathrm{mL})$ following a ROC analysis. On univariate analysis using a threshold of preoperative CA125 levels (at $28 \mathrm{U} / \mathrm{mL}$ ) correlated with older age group ( $>80$ years), unfavourable tumour grade (poorly differentiated), unfavourable tissue type (serous, clear cell adenosquamous, and carcinosarcoma), nodal status, and overall survival at 5 years (Table 2). A preoperative CA125 level of more than $28 \mathrm{U} / \mathrm{mL}$ had a sensitivity of $75 \%$, specificity of $76 \%$, a positive predictive value of $35 \%$ and negative predictive value of $96.25 \%$, and a likelihood ratio of 3.12 for predicting nodal disease. Use of threshold of preoperative CA125 level of $28 \mathrm{U} / \mathrm{mL}$ was also a significant predictor of five year survival (log-rank test, $P=0.01$ ) (Figure 1 ) along with 
TABLE 1: Characteristics of patients with endometrial cancer $N=95$.

\begin{tabular}{lc}
\hline Characteristics & $N(\%)$ \\
\hline Age $>80$ years & $19(20.2)$ \\
Unfavourable histopathological tissue type & $15(15.8)$ \\
Unfavourable preoperative grade & $14(14.7)$ \\
CA125 $>28 \mathrm{U} / \mathrm{mL}$ & $28(29.5)$ \\
\hline
\end{tabular}

TABLE 2: Correlation with elevated CA125 (>28 U/mL).

\begin{tabular}{lccc}
\hline Variable & $\begin{array}{c}\text { Odds } \\
\text { ratio }\end{array}$ & CI & $\begin{array}{c}P \\
\text { value }\end{array}$ \\
\hline Age > 80 years & 1.1 & $0.9-1.5$ & 0.01 \\
Unfavourable histopathological tissue type & 1.5 & $1.1-2.1$ & 0.03 \\
Unfavourable preoperative tumour grade & 1.2 & $0.9-1.5$ & 0.02 \\
Nodal involvement & 1.4 & $0.9-2.3$ & 0.03 \\
5-year survival & 2.2 & $0.8-5.6$ & 0.01 \\
\hline
\end{tabular}

(CI: confidence interval; $P$ value based on Pearson Chi square).

higher risk age group ( $>80$ years, $P=0.01$ ) and unfavourable preoperative grade (log-rank test, $P<0.05$ ).

Following Cox multivariate survival analysis to identify preoperative predictive factors overall, unfavourable tissue type was the strongest predictor of overall long term survival (Chi square $=36.5, \mathrm{df}=4$, and $P=0.001$ ) followed by preoperative CA125 (CA125 $>28 \mathrm{U} / \mathrm{mL}, P=0.011$ ) and unfavourable preoperative tumour grade $(P=0.017)$. Interestingly, among the patients with favourable tissue type (endometrioid), preoperative threshold of CA125 level continued to predict overall survival (Chi square $=6.039, \mathrm{df}=2$, and $P=$ 0.02 ) but amongst unfavourable preoperative tumour grade CA125 was a poor predictor of overall survival $(P=0.5)$.

There were no deaths among women with a preoperative serum CA125 less than $12 \mathrm{U} / \mathrm{mL}$; however eleven of the twenty-three deaths $(47.8 \%)$ at five-year follow-up occurred in women with a preoperative CA125 of more than $28 \mathrm{U} / \mathrm{mL}$.

\section{Discussion}

Revised in 2009 FIGO recommendations on initial surgical management of uterine cancer involve a total hysterectomy and bilateral salpingo-oophorectomy. The decision to perform an extended staging with pelvic and para-aortic lymphadenectomy is based on available preoperative data on high risk prognostic variables such as patient age, high grade tumour, and unfavourable histological cancer type. It is widely accepted that high grade disease is associated with up to $30 \%$ of retroperitoneal nodal involvement [60]. The rational for the extended surgery is to assign a more accurate stage to the disease, plan adjuvant therapy accordingly, and offer the patients recruitment into appropriate clinical trials. Additionally, there is a body of evidence which suggests that lymphadenectomy in this group of patients is not only of diagnostic but also of therapeutic benefit [61-67]. Unfavourable histopathological tissue types of uterine cancer are associated with poor prognosis, but they are infrequent generally accounting for less than $10 \%$ of the patients $[68,69]$.

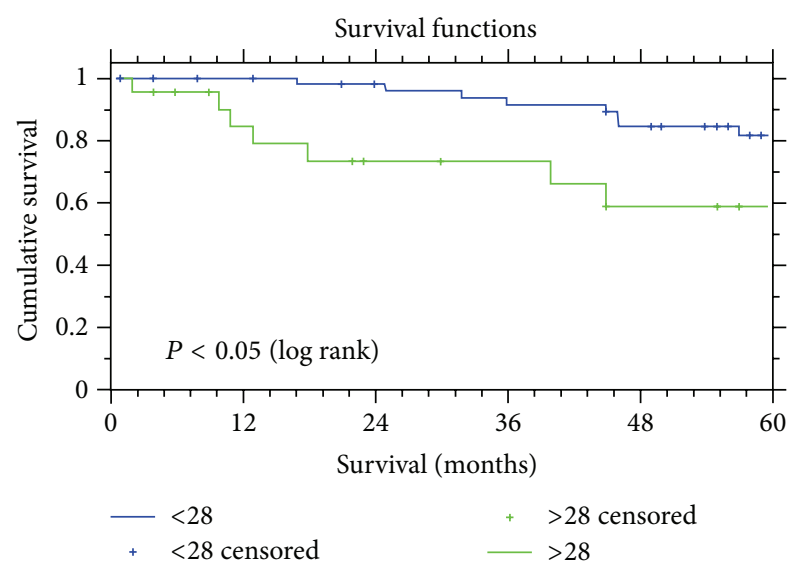

FIGURE 1: Kaplan Meier survival curves and dichotomized CA125 levels.

The majority of endometrial cancers are diagnosed following an office endometrial biopsy or a diagnostic hysteroscopy; however preoperative grade is often upgraded postoperatively in up to $40 \%$ of cases in some reported series [23-25, 27-29].

Another tool for preoperative identification of the metastatic potential of the disease would be useful to help to identify the patients who would benefit from a full retroperitoneal assessment of nodal disease status. It may also help to avoid extensive staging procedures in women with multiple comorbidities when the disease has low potential for recurrence without adversely affecting survival.

There is evidence to suggest that CA125 levels are useful in the management and follow-up of women with uterine cancer. Elevated CA125 levels are not only associated with metastatic disease but recurrent disease as well [50, 70-72].

On review of the available data it appears that the threshold cut-off level for a normal serum CA125 in women with uterine cancer is lower than the traditionally accepted threshold level of $35 \mathrm{U} / \mathrm{mL}$ as used for other clinical settings like ovarian cancer $[50,56,71-73]$.

In 1994, Alagoz et al. first suggested that a lower threshold of CA125 would be appropriate for use in endometrial cancer [74]. Recent studies have suggested that a cut-off level of $20 \mathrm{U} / \mathrm{mL}$ may be appropriate threshold to identify extrauterine spread [50]. Some other studies used the cutoff of $35 \mathrm{U} / \mathrm{mL}[43,54,75]$. Unfortunately there is no study with a large number of participants and no widely accepted threshold level of CA125 to base practice on.

The analysis in this study suggests adopting a threshold level of $28 \mathrm{U} / \mathrm{mL}$. This is consistent and within the range of the CA125 threshold levels as suggested by the other investigators.

A preoperative CA125 assay among the women with uterine cancer correlated with known prognostic variables such as age, cell type, and stage and overall long term survival. At a CA125 level of more than $28 \mathrm{U} / \mathrm{mL}$, there was a three times greater likelihood of identifying nodal disease and the negative predictive value for nodal disease at a level below $28 \mathrm{U} / \mathrm{mL}$ was $95 \%$ among our patients. This is as good as the reported rates of other investigators using 
more expensive and variably available sophisticated imaging modalities. With regard to a long term survival, threshold of preoperative CA125 level of $28 \mathrm{U} / \mathrm{mL}$ correlated with overall five-year survival and continued to do so in the favourable (endometrioid) cell type as well.

A preoperative CA125 assay for women with uterine cancer is a simple, inexpensive, reproducible, and objective test which provides additional information regarding the risk of metastatic disease and ultimate prognosis (long term survival). It provides useful information to clinicians, which could help to individualize and tailor treatment accordingly. Patients with a low likelihood of metastatic/extrauterine disease (favourable histopathological tissue type and CA125 < $28 \mathrm{U} / \mathrm{mL}$ in the presented data) and significant comorbidities may also benefit from consideration of vaginal hysterectomy or alternative treatment options rather than an extensive surgical staging procedure. Alternatively, a CA125 above $28 \mathrm{U} / \mathrm{mL}$ may prompt further imaging (to clarify presence or absence of extrapelvic disease) and multidisciplinary discussions as to the best of management plan for the individual (radical surgery/neoadjuvant/adjuvant therapy). It will also facilitate consideration of patients for recruitment to clinical trials.

We therefore feel that a preoperative CA125 level is a valuable preoperative tool which may be utilised to individualise the treatment offered for uterine cancer. Additionally, in the age of cancer waiting time targets and limited available resources, such as in the National Health Service in the United Kingdom, a preoperative CA125 assay will help the clinicians to allocate clinical resources accordingly.

\section{Conflict of Interests}

The authors declare that there is no conflict of interests regarding the publication of this paper.

\section{References}

[1] Statistics OfN, Cancer Statistics Registrations: Registrations of Cancer Diagnosed in 2008, England, 2010.

[2] Unit WCIaS, Cancer Incidence in Wales 2005-2009, edited by Unit WCIaS, 2011.

[3] ISD Online NHS Scotland IaSD, Cancer Incidence, Mortality and Survival data, 2010

[4] P. D. Sasieni, J. Shelton, N. Ormiston-Smith, C. S. Thomson, and P. B. Silcocks, "What is the lifetime risk of developing cancer: the effect of adjusting for multiple primaries," British Journal of Cancer, vol. 105, no. 3, pp. 460-465, 2011.

[5] M. P. Coleman, B. Rachet, L. M. Woods et al., "Trends and socioeconomic inequalities in cancer survival in England and Wales up to 2001," British Journal of Cancer, vol. 90, no. 7, pp. 1367-1373, 2004.

[6] W. J. Louwman, M. J. Aarts, S. Houterman, F. J. van Lenthe, J. W. W. Coebergh, and M. L. G. Janssen-Heijnen, "A 50\% higher prevalence of life-shortening chronic conditions among cancer patients with low socioeconomic status," British Journal of Cancer, vol. 103, no. 11, pp. 1742-1748, 2010.

[7] S. M. Ueda, D. S. Kapp, M. K. Cheung et al., "Trends in demographic and clinical characteristics in women diagnosed with corpus cancer and their potential impact on the increasing number of deaths," American Journal of Obstetrics and Gynecology, vol. 198, no. 2, pp. 218.el-218.e6, 2008.

[8] International Agency for Reseach on Cancer, GLOBOCAN 2008 v, IARC, European age-standardised rates calculated by the Statistical Information Team at Cancer Research UK, 2011.

[9] W. Creasman, "Revised FIGO staging for carcinoma of the endometrium," International Journal of Gynaecology \& Obstetrics, vol. 105, no. 2, p. 109, 2009.

[10] G. Plataniotis, M. Castiglione, and ESMO Guidelines Working Group, "Endometrial cancer: ESMO clinical practice guidelines for diagnosis, treatment and follow-up," Annals of Oncology, vol. 21, supplement 5, pp. v41-v5, 2010.

[11] R. Woolas and D. Oram, "Current developments in the management of endometrial cancer," in The Year Book of the RCOG, pp. 181-193, 1994.

[12] J. V. Bokhman, "Two pathogenetic types of endometrial carcinoma," Gynecologic Oncology, vol. 15, no. 1, pp. 10-17, 1983.

[13] H. B. Salvesen, S. L. Carter, M. Mannelqvist et al., "Integrated genomic profiling of endometrial carcinoma associates aggressive tumors with indicators of PI3 kinase activation," Proceedings of the National Academy of Sciences of the United States of America, vol. 106, no. 12, pp. 4834-4839, 2009.

[14] W. T. Creasman, M. F. Kohler, F. Odicino, P. Maisonneuve, and P. Boyle, "Prognosis of papillary serous, clear cell, and grade 3 stage I carcinoma of the endometrium," Gynecologic Oncology, vol. 95, no. 3, pp. 593-596, 2004.

[15] C. P. Morrow, B. N. Bundy, R. J. Kurman et al., "Relationship between surgical-pathological risk factors and outcome in clinical stage I and II carcinoma of the endometrium: a gynecologic oncology group study," Gynecologic Oncology, vol. 40, no. 1, pp. 55-65, 1991.

[16] C. L. Creutzberg, W. L. J. van Putten, C. C. Wárláin-Rodenhtiis et al., "Outcome of high-risk stage IC, grade 3, compared with stage I endometrial carcinoma patients: the postoperative radiation therapy in endometrial carcinoma trial," Journal of Clinical Oncology, vol. 22, no. 7, pp. 1234-1241, 2004.

[17] R. Manfredi, P. Mirk, G. Maresca et al., "Local-regional staging of endometrial carcinoma: role of MR imaging in surgical planning," Radiology, vol. 231, no. 2, pp. 372-378, 2004.

[18] K. Kinkel, Y. Kaji, K. K. Yu et al., "Radiologic staging in patients with endometrial cancer: a meta-analysis," Radiology, vol. 212, no. 3, pp. 711-718, 1999.

[19] T. D. Barwick, A. G. Rockall, D. P. Barton, and S. A. Sohaib, "Imaging of endometrial adenocarcinoma," Clinical Radiology, vol. 61, no. 7, pp. 545-555, 2006.

[20] A. N. Gordon, A. C. Fleischer, B. S. Dudley et al., "Preoperative assessment of myometrial invasion of endometrial adenocarcinoma by sonography (US) and magnetic resonance imaging (MRI)," Gynecologic Oncology, vol. 34, no. 2, pp. 175-179, 1989.

[21] E. Steiner, O. Eicher, J. Sagemüller et al., "Multivariate independent prognostic factors in endometrial carcinoma: a clinicopathologic study in 181 patients: 10 years experience at the department of obstetrics and gynecology of the mainz university," International Journal of Gynecological Cancer, vol. 13, no. 2, pp. 197-203, 2003.

[22] A. Sanjuán, T. Cobo, J. Pahisa et al., "Preoperative and intraoperative assessment of myometrial invasion and histologic grade in endometrial cancer: role of magnetic resonance imaging and frozen section," International Journal of Gynecological Cancer, vol. 16, no. 1, pp. 385-390, 2006. 
[23] G. H. Eltabbakh, J. Shamonki, and S. L. Mount, "Surgical stage, final grade, and survival of women with endometrial carcinoma whose preoperative endometrial biopsy shows welldifferentiated tumors," Gynecologic Oncology, vol. 99, no. 2, pp. 309-312, 2005.

[24] G. Vorgias, J. Lekka, M. Katsoulis, E. Varhalama, N. Kalinoglou, and T. Akrivos, "Diagnostic accuracy of prehysterectomy curettage in determining tumor type and grade in patients with endometrial cancer," Medscape General Medicine, vol. 5, no. 4, 2003.

[25] X. Wang, Z. Huang, W. Di, and Q. Lin, "Comparison of D\&C and hysterectomy pathologic findings in endometrial cancer patients," Archives of Gynecology and Obstetrics, vol. 272, no. 2, pp. 136-141, 2005.

[26] A. Thanachaiviwat, C. Thirapakawong, C. Leelaphatanadit, and T. Chuangsuwanich, "Accuracy of preoperative curettage in determining tumor type and grade in endometrial cancer," Journal of the Medical Association of Thailand, vol. 94, no. 7, pp. 766-771, 2011.

[27] J. Mitchard and L. Hirschowitz, "Concordance of FIGO grade of endometrial adenocarcinomas in biopsy and hysterectomy specimens," Histopathology, vol. 42, no. 4, pp. 372-378, 2003.

[28] T. G. Stovall, G. J. Photopulos, W. M. Poston, F. W. Ling, and L. G. Sandles, "Pipelle endometrial sampling in patients with known endometrial carcinoma," Obstetrics and Gynecology, vol. 77, no. 6, pp. 954-956, 1991.

[29] A. G. Daniel and W. A. Peters, "Accuracy of office and operating room curettage in the grading of endometrial carcinoma," Obstetrics and Gynecology, vol. 71, no. 4, pp. 612-614, 1988.

[30] L. A. Hardesty, J. H. Sumkin, M. E. Nath et al., "Use of preoperative MR imaging in the management of endometrial carcinoma: cost analysis," Radiology, vol. 215, no. 1, pp. 45-49, 2000.

[31] I. B. Engelsen, I. M. Stefansson, L. A. Akslen, and H. B. Salvesen, "GATA3 expression in estrogen receptor $\alpha$-negative endometrial carcinomas identifies aggressive tumors with high proliferation and poor patient survival," American Journal of Obstetrics and Gynecology, vol. 199, no. 5, pp. 543.el-543.e7, 2008.

[32] I. B. Engelsen, I. Stefansson, L. A. Akslen, and H. B. Salvesen, "Pathologic expression of p53 or p16 in preoperative curettage specimens identifies high-risk endometrial carcinomas," American Journal of Obstetrics and Gynecology, vol. 195, no. 4, pp. 979986, 2006.

[33] M. B. Silverman, P. C. Roche, R. M. Kho, G. L. Keeney, H. Li, and K. C. Podratz, "Molecular and cytokinetic pretreatment risk assessment in endometrial carcinoma," Gynecologic Oncology, vol. 77, no. 1, pp. 1-7, 2000.

[34] S. Oreskovic, D. Babic, D. Kalafatic, D. Barisic, and L. BeketicOreskovic, "A significance of immunohistochemical determination of steroid receptors, cell proliferation factor Ki-67 and protein p53 in endometrial carcinoma," Gynecologic Oncology, vol. 93, no. 1, pp. 34-40, 2004.

[35] J. Trovik, E. Wik, I. Stefansson et al., "Stathmin is superior to AKT and phospho-AKT staining for the detection of phosphoinositide 3-kinase activation and aggressive endometrial cancer," Histopathology, vol. 57, no. 4, pp. 641-646, 2010.

[36] I. B. Engelsen, I. M. Stefansson, R. Beroukhim et al., "HER2/neu expression is associated with high tumor cell proliferation and aggressive phenotype in a population based patient series of endometrial carcinomas," International Journal of Oncology, vol. 32, no. 2, pp. 307-316, 2008.
[37] E. Wik, J. Trovik, O. E. Iversen et al., "Deoxyribonucleic acid ploidy in endometrial carcinoma: a reproducible and valid prognostic marker in a routine diagnostic setting," American Journal of Obstetrics and Gynecology, vol. 201, no. 6, pp. 603.e1603.e7, 2009.

[38] R. C. Bast, T. L. Klug, E. S. John et al., "A radioimmunoassay using a monoclonal antibody to monitor the course of epithelial ovarian cancer," New England Journal of Medicine, vol. 309, no. 15, pp. 883-887, 1983.

[39] R. C. Bast, M. Feeney, H. Lazarus, L. M. Nadler, R. B. Colvin, and R. C. Knapp, "Reactivity of a monoclonal antibody with human ovarian carcinoma," The Journal of Clinical Investigation, vol. 68, no. 5, pp. 1331-1337, 1981.

[40] A. Berchuck, A. P. Soisson, D. L. Clarke-Pearson et al., "Immunohistochemical expression of CA 125 in endometrial adenocarcinoma: correlation of antigen expression with metastatic potential," Cancer Research, vol. 49, no. 8, pp. 2091-2095, 1989.

[41] J. M. Niloff, T. L. Klug, E. Schaetzl, V. R. Zurawski, R. C. Knapp, and R. C. Bast, "Elevation of serum CA125 in carcinomas of the fallopian tube, endometrium, and endocervix," American Journal of Obstetrics and Gynecology, vol. 148, no. 8, pp. 10571058, 1984.

[42] M. Santala, A. Talvensaari-Mattila, and A. Kauppila, "Peritoneal cytology and preoperative serum CA 125 level are important prognostic indicators of overall survival in advanced endometrial cancer," Anticancer Research, vol. 23, no. 3, pp. 3097-3103, 2003.

[43] J. L. Powell, K. A. Hill, B. C. Shiro, S. J. Diehl, and W. H. Gajewski, "Preoperative serum CA-125 levels in treating endometrial cancer," The Journal of Reproductive Medicine, vol. 50, no. 8, pp. 585-590, 2005.

[44] Y. Todo, N. Sakuragi, R. Nishida et al., "Combined use of magnetic resonance imaging, CA 125 assay, histologic type, and histologic grade in the prediction of lymph node metastasis in endometrial carcinoma," American Journal of Obstetrics and Gynecology, vol. 188, no. 5, pp. 1265-1272, 2003.

[45] V. Kukura, G. Zovko, S. Ciglar et al., "Serum CA-125 tumor marker in endometrial adenocarcinoma," European Journal of Gynaecological Oncology, vol. 24, no. 2, pp. 151-153, 2003.

[46] S. Ginath, J. Menczer, Y. Fintsi, E. Ben-Shem, M. Glezerman, and I. Avinoach, "Tissue and serum CA125 expression in endometrial cancer," International Journal of Gynecological Cancer, vol. 12, no. 4, pp. 372-375, 2002.

[47] D. J. Dotters, "Preoperative CA 125 in endometrial cancer: is it useful?" American Journal of Obstetrics and Gynecology, vol. 182, no. 6, pp. 1328-1334, 2000.

[48] H. Jhang, L. Chuang, P. Visintainer, and G. Ramaswamy, "CA 125 levels in the preoperative assessment of advanced-stage uterine cancer," American Journal of Obstetrics and Gynecology, vol. 188, no. 5, pp. 1195-1197, 2003.

[49] N. Takeshima, Y. Shimizu, S. Umezawa et al., "Combined assay of serum levels of CA125 and CA19-9 in endometrial carcinoma," Gynecologic Oncology, vol. 54, no. 3, pp. 321-326, 1994.

[50] A. Yildiz, H. Yetimalar, B. Kasap et al., "Preoperative serum CA 125 level in the prediction of the stage of disease in endometrial carcinoma," European Journal of Obstetrics, Gynecology, and Reproductive Biology, vol. 164, no. 2, pp. 191-195, 2012.

[51] C.-H. Hsieh, C.-C. ChangChien, H. Lin et al., "Can a preoperative CA 125 level be a criterion for full pelvic lymphadenectomy in surgical staging of endometrial cancer?" Gynecologic Oncology, vol. 86, no. 1, pp. 28-33, 2002. 
[52] J. T. Soper, A. Berchuck, G. J. Olt, A. P. Soisson, D. L. ClarkePearson, and R. C. Bast, "Preoperative evaluation of serum CA 125, TAG 72, and CA 15-3 in patients with endometrial carcinoma," American Journal of Obstetrics and Gynecology, vol. 163, no. 4, pp. 1204-1209, 1990.

[53] H. S. Kim, C.-Y. Park, J.-M. Lee et al., "Evaluation of serum CA125 levels for preoperative counseling in endometrioid endometrial cancer: a multi-center study," Gynecologic Oncology, vol. 118, no. 3, pp. 283-288, 2010.

[54] B. P. Goksedef, H. Gorgen, S. Y. Baran, M. Api, and A. Cetin, "Preoperative serum CA 125 level as a predictor for metastasis and survival in endometrioid endometrial cancer," Journal of Obstetrics and Gynaecology Canada, vol. 33, no. 8, pp. 844-850, 2011.

[55] I. Takac and B. Gorisek, "Serum CA 125 levels and lymph node metastasis in patients with endometrial cancer," Wiener Klinische Wochenschrift, vol. 118, no. 2, supplement, pp. 62-65, 2006.

[56] N. P. Koper, L. F. Massuger, C. M. Thomas, L. A. Kiemeney, and A. L. Verbeek, "Serum CA 125 measurements to identify patients with endometrial cancer who require lymphadenectomy," Anticancer Research, vol. 18, no. 3, pp. 1897-1902, 1998.

[57] A. K. Sood, R. E. Buller, R. A. Burger, J. D. Dawson, J. I. Sorosky, and M. Berman, "Value of preoperative CA 125 level in the management of uterine cancer and prediction of clinical outcome," Obstetrics and Gynecology, vol. 90, no. 3, pp. 441-447, 1997.

[58] S. M. Smith and M. S. Hoffman, "The role of vaginal hysterectomy in the treatment of endometrial cancer," American Journal of Obstetrics and Gynecology, vol. 197, no. 2, pp. 202.el-202.e7, 2007.

[59] J. K. Chan, Y. G. Lin, B. J. Monk, K. Tewari, J. D. Bloss, and M. L. Berman, "Vaginal hysterectomy as primary treatment of endometrial cancer in medically compromised women," Obstetrics and Gynecology, vol. 97, no. 5, part 1, pp. 707-711, 2001.

[60] W. T. Creasman, C. P. Morrow, B. N. Bundy, H. D. Homesley, J. E. Graham, and P. B. Heller, "Surgical pathologic spread patterns of endometrial cancer: a gynecologic oncology group study," Cancer, vol. 60, supplement 8, pp. 2035-2041, 1987.

[61] G. A. Viani, B. F. Patia, A. C. Pellizzon et al., "High-risk surgical stage 1 endometrial cancer: analysis of treatment outcome," Radiation Oncology, vol. 1, article 24, 2006.

[62] E. L. Trimble, C. Kosary, and R. C. Park, "Lymph node sampling and survival in endometrial cancer," Gynecologic Oncology, vol. 71, no. 3, pp. 340-343, 1998.

[63] H. Watari, Y. Todo, M. Takeda, Y. Ebina, R. Yamamoto, and N. Sakuragi, "Lymph-vascular space invasion and number of positive para-aortic node groups predict survival in node-positive patients with endometrial cancer," Gynecologic Oncology, vol. 96, no. 3, pp. 651-657, 2005.

[64] C. V. Lutman, L. J. Havrilesky, J. M. Cragun et al., "Pelvic lymph node count is an important prognostic variable for FIGO stage I and II endometrial carcinoma with high-risk histology," Gynecologic Oncology, vol. 102, no. 1, pp. 92-97, 2006.

[65] Y. Yokoyama, H. Maruyama, S. Sato, and Y. Saito, "Indispensability of pelvic and paraaortic lymphadenectomy in endometrial cancers," Gynecologic Oncology, vol. 64, no. 3, pp. 411-417, 1997.

[66] M. N. Barnes and L. C. Kilgore, "Complete surgical staging of early endometrial adenocarcinoma: optimizing patient outcomes," Seminars in Radiation Oncology, vol. 10, no. 1, pp. 3-7, 2000 .
[67] K. W. Lo, T. H. Cheung, M. Y. Yu, S. F. Yim, and T. K. Chung, "The value of pelvic and para-aortic lymphadenectomy in endometrial cancer to avoid unnecessary radiotherapy," International Journal of Gynecological Cancer, vol. 13, no. 6, pp. 863869, 2003.

[68] T. O. Wilson, K. C. Podratz, T. A. Gaffey, G. D. Malkasian, P. C. O'Brien, and J. M. Naessens, "Evaluation of unfavorable histologic subtypes in endometrial adenocarcinoma," American Journal of Obstetrics and Gynecology, vol. 162, no. 2, pp. 418-426, 1990.

[69] T. W. Burke, P. B. Heller, J. E. Woodward, S. A. Davidson, W. J. Hoskins, and R. C. Park, "Treatment failure in endometrial carcinoma," Obstetrics and Gynecology, vol. 75, no. 1, pp. 96-101, 1990.

[70] P. G. Rose, R. M. Sommers, F. R. Reale, R. E. Hunter, L. Fournier, and B. E. Nelson, "Serial serum CA 125 measurements for evaluation of recurrence in patients with endometrial carcinoma," Obstetrics and Gynecology, vol. 84, no. 1, pp. 12-16, 1994.

[71] J. M. Duk, J. G. Aalders, G. J. Fleuren, and H. W. de Bruijn, "CA 125: a useful marker in endometrial carcinoma," American Journal of Obstetrics and Gynecology, vol. 155, no. 5, pp. 10971102, 1986.

[72] B. Patsner, W. J. Mann, H. Cohen, and M. Loesch, "Predictive value of preoperative serum CA 125 levels in clinically localized and advanced endometrial carcinoma," American Journal of Obstetrics and Gynecology, vol. 158, no. 2, pp. 399-402, 1988.

[73] P. L. Cherchi, S. Dessole, G. A. Ruiu et al., "The value of serum CA 125 and association CA 125/CA 19-9 in endometrial carcinoma," European Journal of Gynaecological Oncology, vol. 20, no. 4, pp. 315-317, 1999.

[74] T. Alagoz, R. E. Buller, M. Berman, B. Anderson, A. Manetta, and P. Disaia, "What is a normal CA125 level?" Gynecologic Oncology, vol. 53, no. 1, pp. 93-97, 1994.

[75] A. Sebastianelli, M. C. Renaud, J. Grégoire, M. Roy, and M. Plante, "Preoperative CA 125 tumour marker in endometrial cancer: correlation with advanced stage disease," Journal of Obstetrics and Gynaecology Canada, vol. 32, no. 9, pp. 856-860, 2010. 


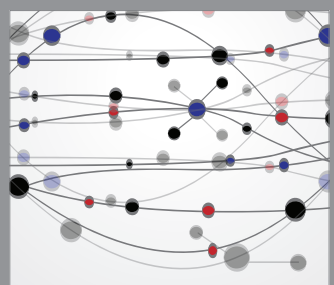

The Scientific World Journal
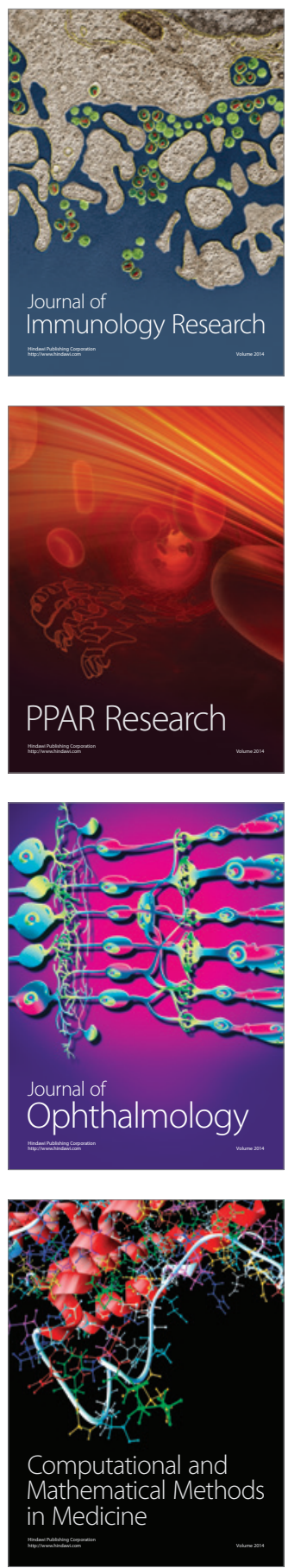

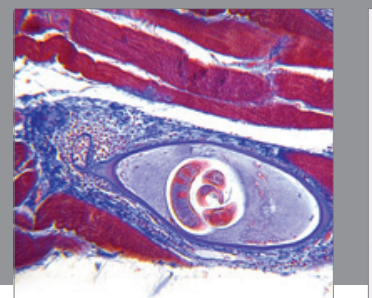

Gastroenterology

Research and Practice
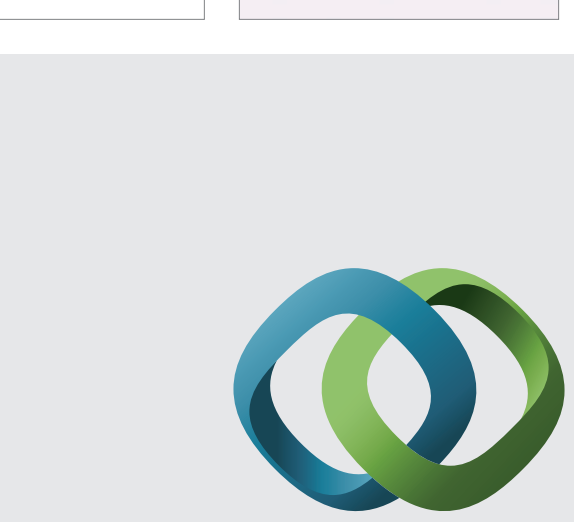

\section{Hindawi}

Submit your manuscripts at

http://www.hindawi.com
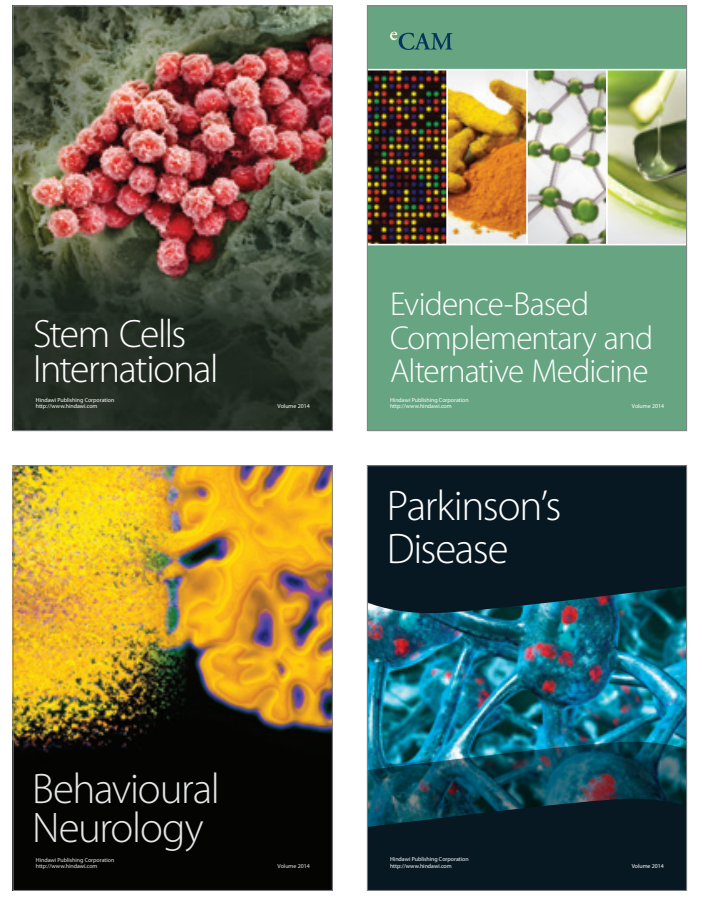
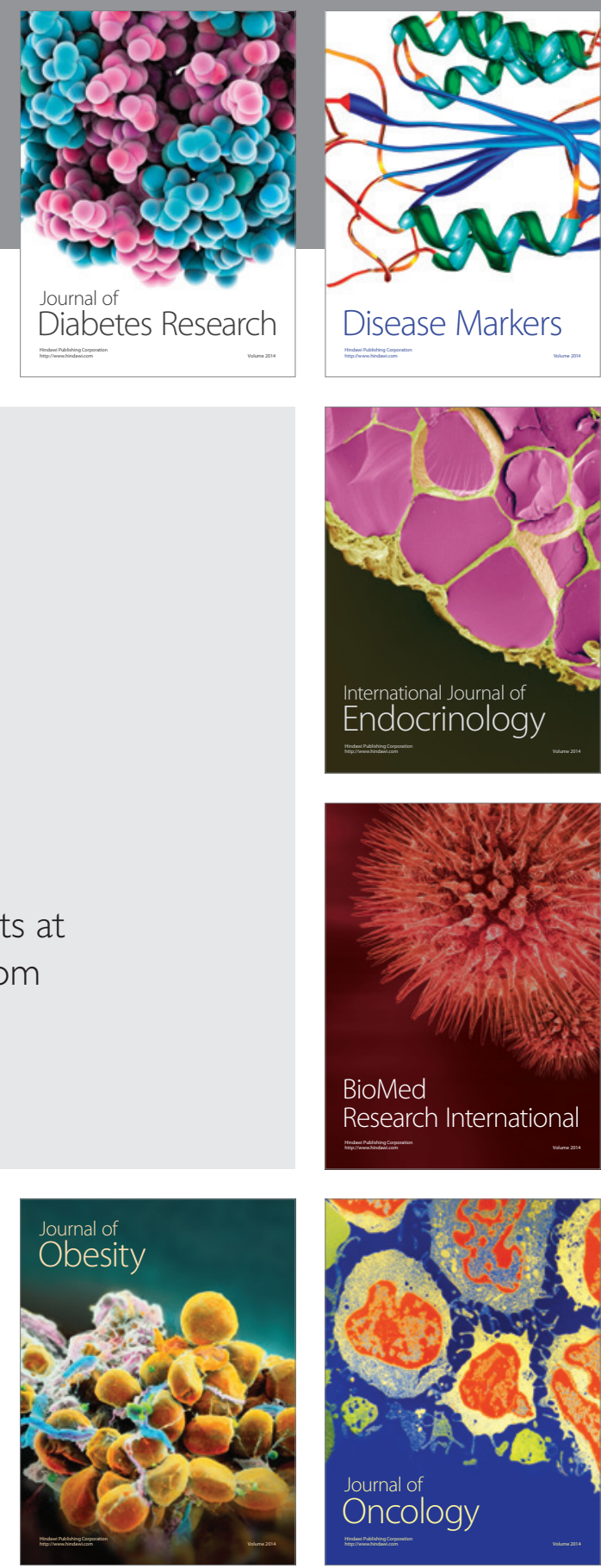

Disease Markers
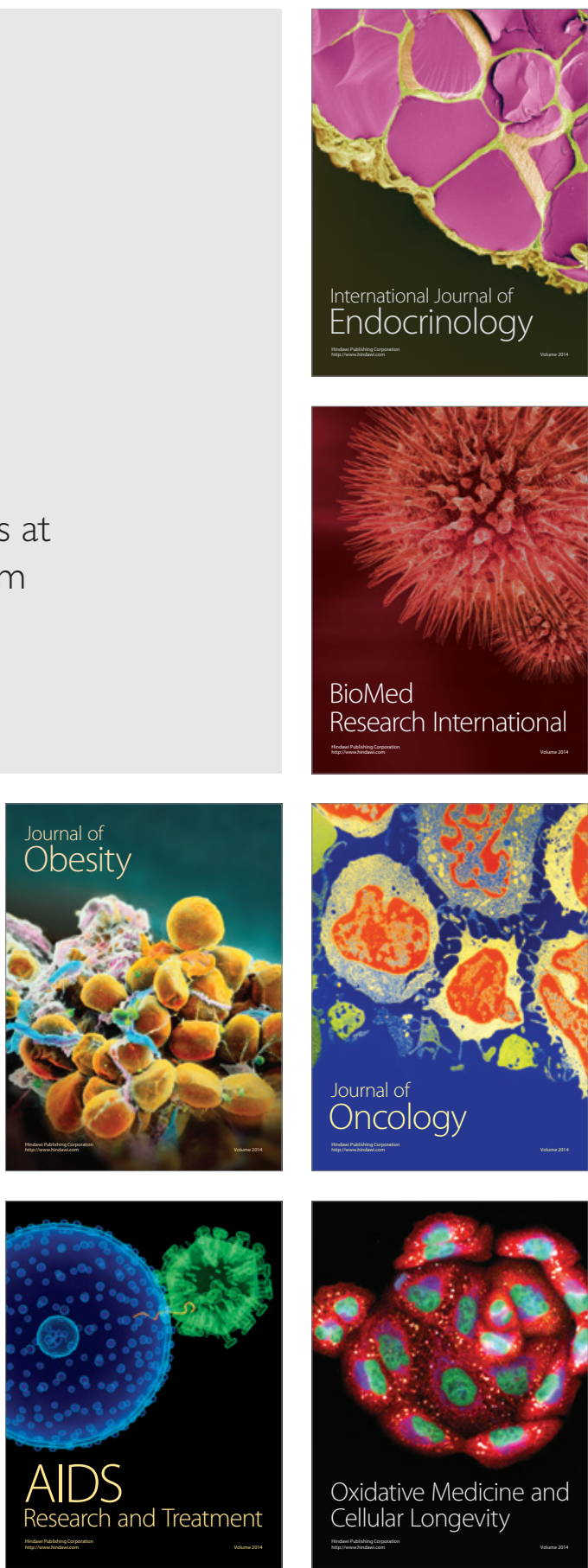